\title{
Estudo longitudinal da densidade mineral óssea de cães Golden Retriever hígidos, portadores e afetados pela distrofia muscular
}

Robson Fortes GIGLIO

Cássio Ricardo Auada

FERRIGNO ${ }^{2}$

Franklin de Almeida

STERMAN ${ }^{2}$

Ana Carolina Brandão de Campos Fonseca PINTO² Júlio César de Carvalho BALIEIRO $^{3}$

Carlos Eduardo AMBROSIO ${ }^{2}$

Daniele dos Santos

MARTINS ${ }^{2}$

Ana Rita LIMA²

Angelica Paula GRANDO

Maria Angélica MIGLINO²

Mayana ZATZ4

\section{Correspondência para:}

Cássio Ricardo Auada Ferrigno Derpartamento de Cirurgia, Av. Prof. Dr. Orlando Marques de Paiva, 87, Cidade Universitária "Armando Salles de Oliveira", São Paulo, São Paulo. CEP:05508-000

Recebido para publicação: 24/01/2008 Aprovado para publicação: 29/06/2009

\author{
1 - Diagnostic Imaging Intern, College of Veterinary Medicine, University of \\ Florida, USA \\ 2 - Faculdade de Medicina Veterinária e Zootecnia da Universidade de São \\ Paulo, São Paulo-SP \\ 3 - Faculdade de Zootecnia e Engenharia de Alimentos da Universidade de São \\ Paulo, Pirassununga-SP \\ 4 - Instituto de Biociências da Universidade de São Paulo, São Paulo-SP
}

Resumo

A Distrofia Muscular do Golden Retriever (GRMD) é considerada o modelo mais apropriado da Distrofia Muscular de Duchenne (DMD) que acomete humanos. Diminuição na Densidade Mineral Óssea (DMO) já foi descrita em meninos com DMD, ambulantes e nãoambulantes. A Densitometria Óptica Radiográfica (DOR) é um método de análise para quantificação da matéria mineral óssea. Este foi realizado por meio de radiografias simples da região proximal da tíbia direita ao lado de escala de alumínio. Quinze cães da raça Golden Retriever, sendo cinco normais, cinco portadores e cinco afetados pela distrofia, foram radiografados mensalmente, dos três aos nove meses de idade. Estas radiografias foram analisadas por meio do software de análise de imagens (ImageLab, Softium ${ }^{\circledR}$ ). O estudo revelou que a região epifisária possui maior densidade mineral óssea (DMO), seguida pela região metafisária e diafisária. Houve uma tendência de aumento da DMO nas três regiões avaliadas dos três grupos durante o experimento. A região metafisária proximal da tíbia demonstrou ser o sitio de eleição para a leitura da DMO, por ser o local com menor correlação e influencia do peso corpóreo e por promover estimativas médias consideradas significativas entre grupos avaliados mais cedo que nas demais regiões. O potencial de diagnóstico deste exame densitométrico, em relação a GRMD, foi considerado baixo, porém, demonstrou ter grande potencial no acompanhamento do progresso desta doença por apresentar alta sensibilidade para detecção de variações na densidade mineral óssea.

\section{Introdução}

A forma mais comum de distrofia muscular em humanos é o tipo Duchenne (DMD), com incidência aproximada de um caso a cada 3.500 nascimentos masculinos, sendo fatal no período entre a segunda e a terceira década de vida. Esta ocorre devido mutações no gene da produção da proteína distrofina, responsável pela adesão matriz extracelular do citoesqueleto. Este gene se localiza no cromossomo $\mathrm{X}$, afetando predominantemente machos, por estes possuírem apenas um cromossomo X. . $^{1,2,3,4}$ Diminuição na Densidade Mineral Óssea (DMO) já foi descrita em meninos com DMD, ambulantes e não-ambulantes., ${ }^{5,6,7}$

Distrofias musculares ligadas ao cromossomo X, similares a Duchenne, foram descritas no cão, gato e camundongo. A Distrofia Muscular do Golden Retriever (DMGR) é considerada o modelo animal mais apropriado devido sua analogia com a DMD tanto em relação ao genótipo quanto 
ao fenótipo. ${ }^{1,3,8,9,10,11,12,13}$ Cães afetados por esta forma de distrofia apresentam sinais clínicos por volta de oito a dez semanas de vida. Este sinais incluem fraqueza generalizada, marcha alterada devido a curta amplitude de movimento das articulações e dificuldade de apreensão e deglutição do alimento. ${ }^{2,13}$ Seu diagnóstico se faz por meio da enzima creatina quinase sérica, usualmente 300 vezes maior do que os valores normais, e posterior confirmação em biopsias musculares, onde se observa severa hipercontração e necrose segmentar com fagocitose e regeneração.,13

O presente trabalho teve a finalidade de verificar e avaliar a densidade mineral óssea dos cães da raça Golden Retriever normais, afetados e portadores da DMGR de forma longitudinal (dos três aos nove meses de idade), correlacionando a densidade mineral óssea com as variáveis peso corpóreo, idade e grupo e as regiões (epífise, metáfise e diáfise proximais da tíbia) estudadas, e, subjetivamente, comentar sobre o potencial de diagnóstico e de acompanhamento da evolução da DMGR por meio da técnica de densitometria óptica radiográfica (DMO).

\section{Material e Método}

O trabalho foi aprovado pela Comissão de Bioética da Faculdade de Medicina Veterinária e Zootecnia da Universidade de São Paulo sob o número de registro 446/2004.

Foram utilizados 15 cães da raça Golden Retriever, nascidos de três diferentes ninhadas, filhos de mães portadoras da GRMD e pais hígidos. Estes foram distribuídos em três grupos: cinco cães afetados pela DMGR (Grupo I), cinco cães portadores da DMGR (Grupo II) e cinco cães hígidos (Grupo III), por meio da análise da enzima creatinina quinase sérica e posteriormente confirmados com os resultados da análise do DNA das células sanguíneas pelo GFX Genomic Blood DNA Purification Kit (Amersham Pharmacia $^{\circledR}$.
Todos os cães foram pesados e radiografados mensalmente para estudo da densidade mineral óssea. Este se fez por meio de radiografia simples da tíbia direita, paralela a escala de alumínio confeccionada com liga específica e padronizada internacionalmente (Liga de alumínio 2026, ABNT).

Dos três meses de idade até o fechamento do disco epifisário proximal da tíbia direita aos nove meses de idade, os cães foram radiografados em incidência médiolateral, utilizando-se o aparelho de raio X da marca Ray-tec modelo RT 500/125, com chassis de $18 \times 24 \mathrm{~cm}$, com écrans intensificadores Kodak Lanex X-Omatic Regular Screens (Kodak Eastman Company $^{\circledR}$ ) e filme radiológico no tamanho $18 \times 24 \mathrm{~cm}$, RP-X-OMAT (Kodak Bras. Com. e Ind. Ltda). A técnica radiográfica utilizada nos dois primeiros meses de estudo foi de: quilovoltagem de 40 quilovolts $(\mathrm{kV})$, miliamperagem de 100 miliampères $(\mathrm{mA})$, tempo de exposição de 0,025 segundos (s) e distância foco-filme de $100 \mathrm{~cm}$ para todos os animais. Em virtude do rápido crescimento dos animais, a partir do terceiro mês de estudo, correspondente ao quinto mês de idade, até o término do estudo houve incremento da quilovoltagem para 44 quilovolts $(\mathrm{kV})$.

A revelação dos filmes foi feita na processadora automática, RP-X-OMAT Processor (Kodak Eastman Company ${ }^{\circledR}$ ). O processo de digitalização da imagem radiográfica foi feito no scanner de mesa modelo HP Scanjet 6300C (HewlettPackard $\left.^{\circledR}\right), \quad$ com adaptador para transparências modelo ScanJet XPA $\left(\right.$ Hewlett-Packard $\left.{ }^{\circledR}\right)$. As imagens foram analisadas com o auxílio do programa ImageLab (Softium ${ }^{\circledR}$, Sistemas de Informática), que compara a densidade média da região do osso selecionada com a densidade média dos degraus da escala de alumínio, determinando a equivalência em milímetros de alumínio da densidade da região selecionada.

Neste estudo, três regiões foram estudadas: epífise, metáfise e diáfise proximais 
da tíbia direita. Com o intuito de que a densidade mineral óssea fosse a mais fidedigna possível, padronizou-se que as áreas selecionadas seriam figuras geométricas, desenhadas de acordo com alguns acidentes anatômicos da tíbia tomados como pontos de referencia. Com isto, foi calculado o valor de densidade óptica em milímetros de alumínio de cada região (Figura 1). A demarcação da área e o cálculo da densidade óptica foram obtidos três vezes em cada região, sendo o resultado utilizado para a avaliação a média dos valores obtidos das leituras.

Para obtenção da estatística descritiva as variáveis peso corpóreo (em kg) e os valores da densidade mineral óssea das três regiões analisadas (em $\mathrm{mmAl}$ ) utilizou-se o procedimento PROC MEANS do programa Statistical Analysis System, versão 8.0. ${ }^{14}$ Para a análise de correlação entre as regiões ósseas analisadas com o peso corpóreo nas diferentes idades (em meses) no período experimental utilizou-se o Teste de Pearson do procedimento PROC CORR do mesmo programa supracitado.

\section{Resultados e Discussão}

Mensalmente, dos três aos nove meses de idade, o resumo dos efeitos de grupo, idade e interação grupo-idade avaliados para todas variáveis estudadas (peso corpóreo, densidade mineral óssea da epífise, metáfise e diáfise proximais da tíbia direita) foi altamente significativo $(\mathrm{P}<0,01)$, indicando dependência dos grupos avaliados frente às diferentes idades. A estimativa média das variáveis peso corpóreo, densidade mineral óssea da epífise, metáfise e diáfise proximal da tíbia direita foi processada e está demonstrada na tabela 1 e figuras 2 e 3 .

O processamento das imagens, a delimitação precisa da região escolhida e a

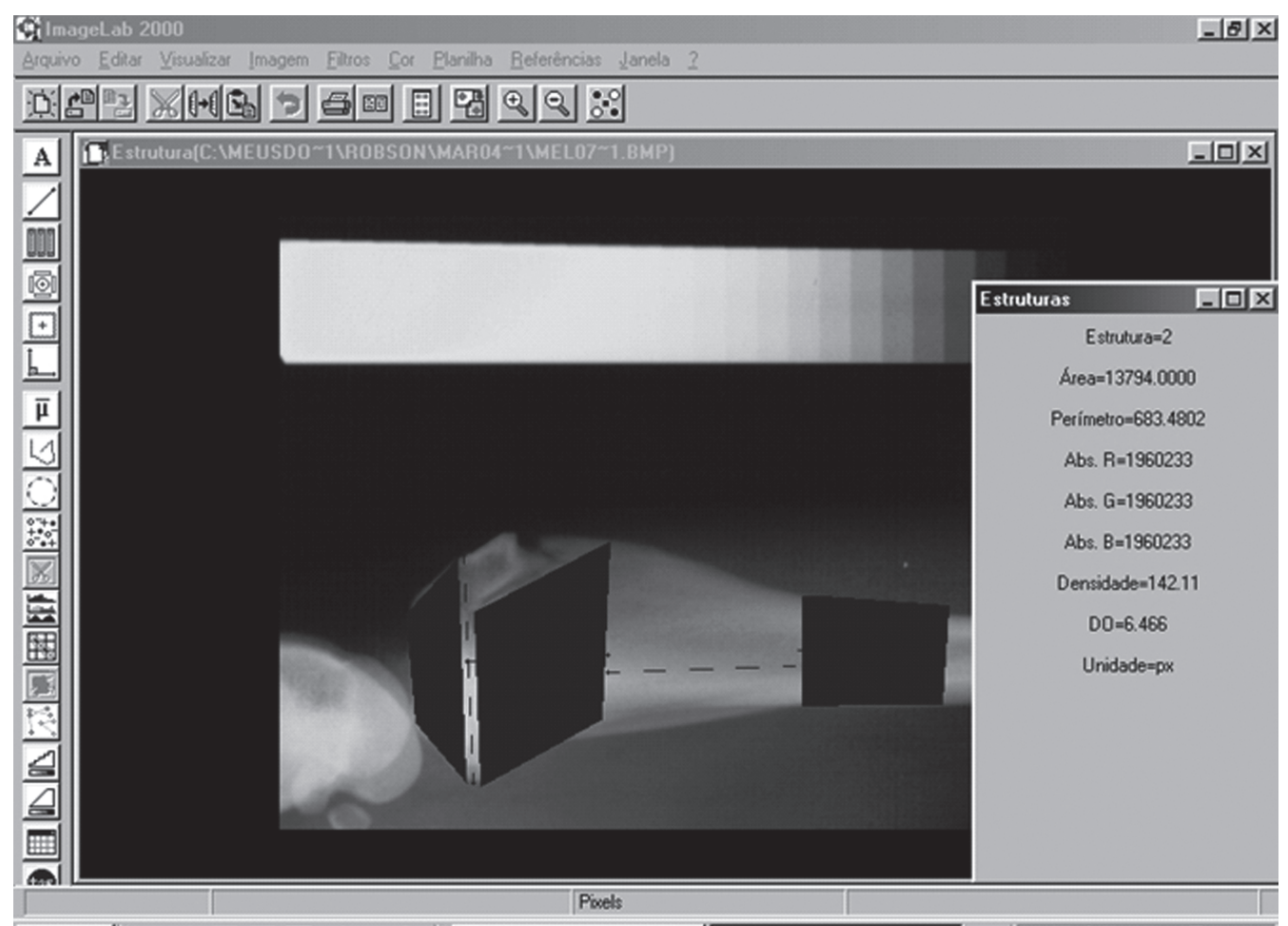

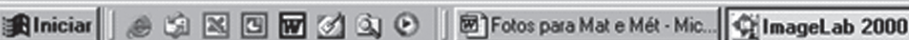

Figura 1 - Figura esquematica demonstrando a seleção das regiões osseas analisadas referenciadas pelo três quadriláteros pretos. Identifica-se no interior da figura a direita, quadro demonstrando os resultados da leitura da densidade óptica (DO) da região metafisária 
Tabela 1 - Estimativas médias do peso corpóreo em $\mathrm{kg}$, e da densidade mineral óssea (DMO), em mmAl, das regiões epifisária, metafisária e diafisária proximal da tíbia direita dos grupos avaliados: Afetados pela DMGR (A), portadores (P) e hígidos (H) dentro das idades, em meses - São Paulo - 2005

\begin{tabular}{|c|c|c|c|c|c|}
\hline Idade (m) & Grupo & Peso Corpóreo(kg) & $\begin{array}{c}\text { DMO Epifise } \\
\text { (mmAl) }\end{array}$ & $\begin{array}{c}\text { DMO Metáfise } \\
\text { (mmAl) }\end{array}$ & $\begin{array}{c}\text { DMO Diá fise } \\
\text { (mmAl) }\end{array}$ \\
\hline 3 & A & $3,120^{\mathrm{a}}$ & $2,667^{a}$ & $2,105^{a}$ & $1,985^{\mathrm{a}}$ \\
\hline 3 & $\mathbf{P}$ & $2,400^{a}$ & $2,238^{a}$ & $1,673^{a}$ & $1,421^{\mathrm{a}}$ \\
\hline 3 & $\mathrm{H}$ & $2,200^{a}$ & $2,474^{a}$ & $1,775^{a}$ & $1,585^{a}$ \\
\hline 4 & A & $5,720^{a}$ & $3,574^{a}$ & $3,010^{\mathrm{a}}$ & $2,460^{\mathrm{a}}$ \\
\hline 4 & $\mathbf{P}$ & $3,720^{a}$ & $3,520^{\mathrm{a}}$ & $2,891^{a}$ & $2,583^{\mathrm{a}}$ \\
\hline 4 & $\mathrm{H}$ & $3,540^{\mathrm{a}}$ & $3,463 \mathrm{a}$ & $2,928^{\mathrm{a}}$ & $2,535^{\mathrm{a}}$ \\
\hline 5 & A & $10,400^{\mathrm{a}}$ & $3,863^{a}$ & $3,421 \mathrm{a}$ & $2,839^{\mathrm{a}}$ \\
\hline 5 & $\mathbf{P}$ & $9,040^{\mathrm{a}}$ & $4,863^{a}$ & $4,097^{\mathrm{a}}$ & $3,278^{a}$ \\
\hline 5 & $\mathrm{H}$ & $10,875^{a}$ & $6,689^{b}$ & $5,453^{b}$ & $4,478^{a}$ \\
\hline 6 & A & $14,725^{\mathrm{a}}$ & $5,112^{a}$ & $4,059^{\mathrm{a}}$ & $3,620^{a}$ \\
\hline 6 & $\mathbf{P}$ & $15,200^{\mathrm{a}}$ & $5,954^{a, b}$ & $5,112^{b}$ & $4,082^{\mathrm{a}}$ \\
\hline 6 & $\mathrm{H}$ & $18,875^{3}$ & $6,835^{b}$ & $5,435^{b}$ & $4,282^{\mathrm{a}}$ \\
\hline 7 & $\mathrm{~A}$ & $16,425^{3}$ & $5,144^{\mathrm{a}}$ & $4,071^{a}$ & $3,868^{\mathrm{a}}$ \\
\hline 7 & $\mathbf{P}$ & $19,020^{a b}$ & $6,458^{b}$ & $5,347^{b}$ & $4,688^{b}$ \\
\hline 7 & $\mathrm{H}$ & $22,950^{\circ}$ & $7,256^{b}$ & $5,774^{b}$ & $4,935^{b}$ \\
\hline 8 & A & $18,000^{3}$ & $5,852^{\mathrm{a}}$ & $4,716^{\mathrm{a}}$ & $4,330^{\mathrm{a}}$ \\
\hline 8 & $\mathbf{P}$ & $20,100^{a}$ & $6,972^{a}$ & $6,015^{b}$ & $5,236^{b}$ \\
\hline 8 & $\mathrm{H}$ & $22,650^{\mathrm{a}}$ & $6,912^{a}$ & $5,289^{\circ}$ & $5,079^{b}$ \\
\hline 9 & A & $18,767^{\mathrm{a}}$ & $5,760^{\mathrm{a}}$ & $4,343^{\mathrm{a}}$ & $4,328^{\mathrm{a}}$ \\
\hline 9 & $\mathbf{P}$ & $22,540^{a b}$ & $6,999^{b}$ & $5,612^{b}$ & $5,248^{b}$ \\
\hline 9 & $\mathrm{H}$ & $24,950^{b}$ & $8,591^{c}$ & $6,558^{c}$ & $5,770^{b}$ \\
\hline
\end{tabular}

Médias em uma mesma coluna dentro do mesmo mês e com letras iguais não diferem entre si ao nível de, pelo menos $5 \%$ de probabilidade, pelo teste $t$

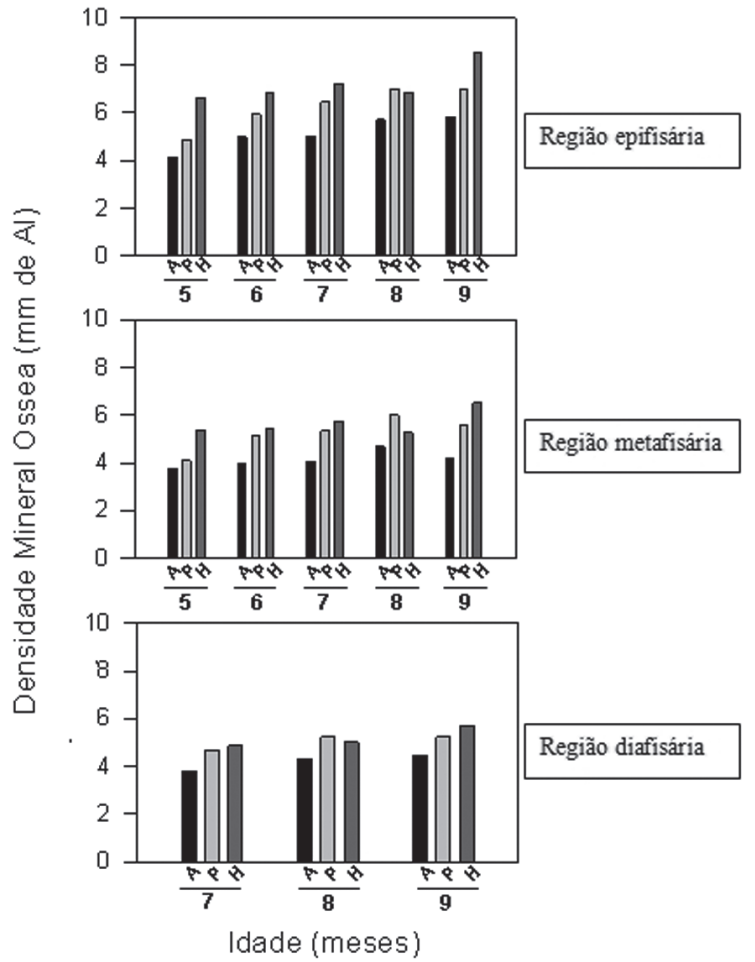

Figura 2 - Gráfico de barras paralelas das estimativas da densidade mineral óssea (DMO), em mmAl, das regiões epifisária, metafisária e diafisária proximal da tíbia direita dos grupos avaliados, afetados pela DMGR $(A)$, portadores $(\mathrm{P})$ e hígidos $(\mathrm{H})$, dentro das idades, em meses, consideradas significativas para o desdobramento da interação grupo x idade - São Paulo - 2005 


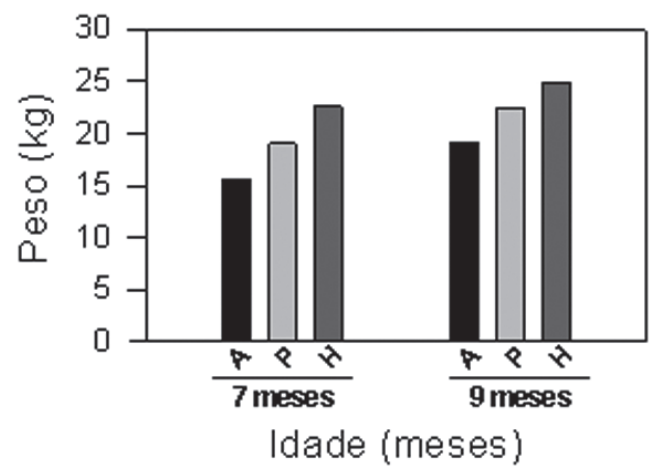

Figura 3 - Estimativas médias do peso corpóreo, em kg, dos grupos avaliados, afetados pela DMGR (A), portadores $(\mathrm{P})$ e hígidos $(\mathrm{H})$, dentro das idades, em meses, consideradas significativas para o desdobramento da interação grupo $x$ idade - São Paulo - 2005

verificação de valores muito próximos nas três medidas feitas para cada uma das três região em cada radiografia permitem concluir que a DOR possui fácil execução, baixo custo, precisão, sensibilidade e reprodutibilidade, como afirmam outros autores que utilizaram o mesmo programa computacional ImageLab Softium $^{\circledR}$, Sistemas de Informática) $)^{15,16,17,18,19}$ e outros que utilizaram a mesma técnica densitométrica, entretanto com outros programas de processamento de imagens ${ }^{20,21,22}$, viabilizando sua realização na Medicina Veterinária.

Os fatores que levaram a escolha da tíbia para a análise da densidade mineral óssea neste estudo, foram: localização anatômica, por possuir pequena quantidade de tecidos moles ao seu redor, produzindo assim pouca influencia na leitura da DMO; e ainda de acordo com o perfil de evolução desta doença, já que o enrijecimento e atrofia muscular dos membros pélvicos são freqüentemente observados nos cães afetados pela Distrofia Muscular do Golden Retriever ${ }^{17,11,13}$ e constatado clinicamente na evolução da doença dos cães deste experimento.

A única alteração realizada no período experimental foi o aumento da quilovoltagem de 40 para $44 \mathrm{kV}$ no terceiro mês de experimento (quinto mês de idade dos cães), que se manteve até seu término aos nove meses de idade. Isto se fez necessário devido ao grande incremento em massa corpórea dos cães dos três grupos entre o quarto e quinto mês de vida, no qual o peso corpóreo foi quase triplicado. Esta alteração se torna possível devido ao recurso de equalização de curvas dos tons de cinza que o programa ImageLab (Softium ${ }^{\circledR}$, Sistemas de Informática) fornece, como informado por alguns autores. ${ }^{13,15}$

Houve grande variação do peso corpóreo e da DMO nos cães afetados pela DMGR ao longo do período experimental. Isto foi observado também em humanos ${ }^{5,6,7}$ e se atribui a grande variação de manifestação de sinais clínicos entre os indivíduos acometidos.

Nos dois primeiros meses do estudo, ou seja, no terceiro e quarto meses de vida dos cães, o peso corpóreo e a DMO dos cães afetados obteve valores maiores do que observado nos outros grupos. Isto pode ser explicado pelo cuidado intensivo dedicado aos animais afetados desde seu nascimento e também pela natureza degenerativa e progressiva do curso esperado desta doença, apontado também por outros autores., 2,13,15

Nos três grupos avaliados, os valores médios de densidade mineral óssea na região epifisária foram mais altos, seguidos pela região metafisária e diafisária, respectivamente. Este fato pode ser explicado segundo observações de Junqueira e Carneiro ${ }^{23}$, onde a epífise é constituída por osso esponjoso, com uma delgada camada superficial de osso compacto organizada em forma lamelar (ou secundária), sendo esta mais densa que a metáfise de um animal em crescimento que se constitui, predominantemente, por tecido ósseo imaturo (ou primário), no qual há menor mineralização. Embora composta quase que totalmente por osso compacto, delimitando o canal medular, a diáfise possui menor densidade mineral óssea em relação às outras porções ósseas; porque quando se seleciona esta região, o a área selecionada para o cálculo do valor densitométrico inclui o canal medular que possui menor radiopacidade por conter a medula óssea.

De forma geral houve um incremento 
mensal da densidade mineral óssea das três regiões estudadas dos cães afetados pela DMGR, com exceção do valor das estimativas médias da região metafisária do nono mês de idade, a qual diminuiu seu valor em relação à leitura do mês anterior. Este decréscimo da DMO da região metafisária no nono mês pode ter ocorrido devido a progressão da doença ou devido a alguma alteração secundaria facilitada pela distrofia muscular, como alterações respiratórias (pneumonia por aspiração e fibrose diafragmática), de deglutição (hipertrofia da musculatura da ligua), observado nestes cães, semelhantes ao reportado em humanos, ambulantes ou não. Entretanto, poucos estudos sobre a densidade mineral óssea em humanos afetados por distrofia muscular de Duchenne foram publicados. Osteoporose foi bem caracterizada em meninos com DMD ambulante ${ }^{5,6,7}$, a qual se manifestou primeiramente na região metafisária, zona de maior atividade metabólica do osso em crescimento. Para a confirmação desta hipótese há necessidade de realização do exame densitométrico por um maior período experimental.

Pode-se diferenciar os grupo dos cães normais dos cães afetados, por meio de valores estatisticamente significativos, nas regiões epifisária e metafisária proximais da tíbia a partir cinco meses de idade. A diferenciação do grupo dos cães portadores em relação aos afetados, assim como a individualização dos três grupos ocorreu posteriormente.

A região diafisária proximal da tíbia demonstrou ser a região com maior correlação, ou seja, maior influencia, do peso corpóreo por apresentar valores das estimativas médias dos grupos no desdobramento da interação grupo x idade com comportamento semelhantes. Este dado associado com a impossibilidade de diferenciação entre os três grupos por meio dos valores obtidos na região diafisária proximal da tíbia podem ser explicados com a afirmação de outro autor ${ }^{24}$, de que a diáfise é a região de menor variação mineral. Sendo assim, especula-se que a diferenciação entre os três grupos, que foi observada nas outras regiões analisadas, possa ser demonstrada em cães com idade mais avançada, não contemplada no período experimental deste estudo.

Por meio destes dados, observou-se que o peso corpóreo possui grande relação com os valores da DMO nas diferentes regiões ósseas analisadas, em concordância com Giglio ${ }^{17}$ e Muramoto e Sterman ${ }^{18}$.

Observou-se relação estatística altamente significativa $(\mathrm{P}<0,01)$ da interação grupo $\mathrm{x}$ idade com a DMO das regiões avaliadas, impossibilitando, neste estudo, uma relação somente entre a idade e DMO, como feita por Giglio $^{17}$ e Muramoto e Sterman ${ }^{18}$., que demonstrou baixa relação entre estas.

A região metafisária demonstrou ser a região de escolha para a realização das leituras da DMO por possuir menor relação e interferência de variações do peso corpóreo e por possibilitar diferenciação entre animais afetados e hígidos, a partir do quinto mês de idade, e a diferenciação entre os três grupos por valores estatisticamente significativos $(\mathrm{P}<0,05)$ mais cedo que as outras regiões analisadas.

\section{Conclusões}

O estudo revelou que a região epifisária possui maior DMO, seguida pela região metafisária e diafisária, respectivamente, nos três grupos avaliados, ao longo do período experimental, e estas seguiram o comportamento do peso corpóreo. A região metafisária proximal de tíbia demonstrou ser a região de eleição para a leitura da DMO por ser o local estudado com menor correlação e influencia do o peso corpóreo e por promover estimativas médias consideradas significativas entre grupos avaliados mais cedo que nas demais regiões O potencial de diagnóstico do exame densitométrico, foi considerado baixo, comparado a outras modalidades como pela avaliação da enzima creatinina quinase sérica entre outros, por somente apresentar diferença estatisticamente significante entre os cães hígidos e distróficos a partir do 
quinto mês de idade, e significante diferença entre os cães hígidos, portadores e distróficos no nono mês de idade. Entretanto, esta técnica demonstrou ter grande potencial no acompanhamento do progresso desta doença por apresentar alta sensibilidade para detecção de variações na densidade mineral óssea.

\section{Longitudinal study of bone mineral density in healthy, carrier, and affected dogs by Golden Retriever Muscular Dystrophy}

\section{Abstract}

The Golden Retriever Muscular Dystrophy (GRMD) is considered the most appropriate model of the Duchenne Muscular Dystrophy (DMD) in humans. Decrease in Bone Mineral Density (DMO) has been recognized in ambulatory and non-ambulatory boys with DMD. The Radiographic Optical Densitometry is a method to measure the bone mineral content. It was performed radiographing the proximal right tibia next to an aluminum stepwedge. Fifteen Golden Retriever dogs had been used, divided in three groups: Five healthy, five carriers and five affected by GRMD, monthly radiographed, from 3 to 9 months-old. These radiographies were analyzed by image processing software (ImageLab, Softium ${ }^{\circledR}$ ). The proximal epiphysis had higher bone mineral density, followed for the metaphysic and diaphysis, respectively. All regions followed has influence the body weight. There was an increase of the bone mineral density in all regions of the three groups. The proximal metaphysis was thought to be the better region to evaluate the bone mineral density because had less correlation and influence of the body weight, and, also, had different significant values to differentiate the groups earlier than the other regions. The potential diagnostic of this densitometric method in GRMD was considered low, however it demonstrated to have great potential in the clinical recheck of this patients due to the high sensitivity for detection of changes in the bone mineral density.

\section{Referências}

1 BERGMAN, R. L.; INZANA, K. D.; MONROE, W. E.; SHELL, L. G.; LIU, L. A.; ENGVALL, E.; SHELTON, G. D. Dystrophin-deficient muscular dystrophy in a Labrador Retriever. Journal of the American Animal Hospital Association, v. 38, p. 255-261, 2002.

2 BRUMITT, J. W.; ESSMAN, S. C.; KORNEGAY, J. N.; GRAHAM, J. P.; WEBER, W. J.; BERRY, C. R. Radiographic features of Golden Retriever muscular dystrophy. Veterinary Radiology and Ultrasound, $v$. 47, n. 6, p. 574-580, 2006.

3 FLETCHER, S.; CARVILLE, K. S.; HOWELL, J. M.; MANN, C. J.; WILTON, S. D. Evaluation of a short interspersed nucleotide element in the $3^{\prime}$ untranslated region of the defective dystrophyn gene of dogs with muscular dystrophy. American Journal of Veterinary Research, v. 62, n. 12, p. 1964-1968, 2001.

4 SHELTON, G. D.; LIU, L. A.; GUO, L. T.; SMITH, G. K.; CHRISTIANSEN, J. S.; THOMAS, W. B.; SMITH,
Key words: Bone densitometry. Radiology. Dogs. Golden Retriever dogs. Muscular dystrophy.
M. O.; KLINE, K. L.; MARCH, P. A.; FLEGEL, T.; ENGVALL, E. Muscular dystrophy in female dogs. Journal of Veterinary Internal Medicine, v. 15, p. 240244, 2001.

5 APARÍCIO, L. F.; JURKOVIC, M.; DELULLO, J. Decrease bone density in ambulatory patients with Duchenne muscular dystrophy. Journal of Pediatric Orthopedics, v. 22, n. 2, p. 179-181, 2002.

6 BIANCHI, M. L.; MAZZANTI, A.; GALBIATI, E.; SARAIFOGER, S.; DUBINI, A.; CORNELIO, F.; MORANDI, L. Bone mineral density and bone metabolism in Duchenne muscular dystrophy. Osteoporos International, v. 14, p. 761-767, 2003.

7 LARSON, C. M.; HENDERSON, R. C. Bone mineral density and fractures in boys with Duchenne muscular dystrophy. Journal of Pediatric Orthopaedics, v. 20, n. 1, p. 71-74, 2000.

8 COOPER, B. J.; WINAND, N. J.; STEDMAN, H.; VALENTINE, B. A.; HOFFMAN, E. P.; KUNKEL, L. M.; SCOTT, M. O.; FISCHBECK, K. H.; KORNEGAY, J. N.; AVERY, R. J. et al. The homologue of the Duchenne 
locus in defective in X-linked muscular dystrophy in dogs. Nature, v. 334, p. 154-156, 1988.

9 KORNEGAY, J. N.; TULER, S. M.; MILLER, D. M.; LEVESQUE, D. C. Muscular dystrophy in a litter of golden retriever dogs. Muscle Nerve, v. 11, n. 10, p. 1056-1064, 1988.

10 KORNEGAY, J. N. et al. Golden Retriever muscular dystrophy: monitoring for sucess. In: GRIGGS, R. C.; KARPATI, G. Myoblast transfer therapy. New York: Plenum, 1990. p. 267-272.

11 KORNEGAY, J. N.; SHARP, N. J.; SCHUELER, R. O.; BETTS, C. W. Tarsal joint contracture in dogs with Golden Retriever Muscular Dystrophy. Laboratory Animal Science, v. 44, n. 4, p. 331-333, 1994.

12 SCHATZBERG, S. J.; ANDERSON, L. V.; WILTON S. D.; KORNEGAY, J. N.; MANN, C. J.; SOLOMON, G. G.; SHARP, N. J. Alternative dystrophin gene transcripts in Golden Retriever Muscular Dystrophy. Muscle Nerve, v. 21, p. 991-998, 1998.

13 VALENTINE, B. A.; COOPER, B. J.; DE LAHUNTA, A.; O'QUINN, R.; BLUE, J. T. Canine X-linked muscular dystrophy. An animal model of Duchenne muscular dystrophy: clinical studies. Journal of Neurological Sciences, v. 88, n. 3, p. 69-81, 1988.

14 STATISTICAL ANALISYS SYSTEM. SAS User's guide: basic and statistic. Versão 5. Cary, 1995. 1686 p.

15 MACK, P. B.; VOSE, G. P.; NELSON, J. D. New development in equipment for the roentgenographic measurement of bone density. American Journal of Roentnology, v. 82, n. 2, p. 303-310, 1959.

16 OWEN, M. Measurements of the variations in calcification in normal rabbit bone. Journal of Bone Joint Surgery, v. 388, n. 3, p. 762-769, 1956.

17 GIGLIO, R. F.; BALIEIRO, J. C. C.; STERMAN, F. A.; PINTO, A. C. B. C. F.; MIGLINO, M. A.; ZATZ, M.; FERRIGNO, C. R. A. Estudo longitudinal da densidade mineral óssea em cães jovens da raça Golden Retriever: correlações com idade e peso corpóreo. Brazilian Journal of Veterinary Research and Animal Sciences, v. 43, n. 5, p. 681-687, 2006

18 MURAMOTO, C.; STERMAN, F. A. Estabelecimento de valores de densidade mineral óssea (DMO) das regiões diafisárias do rádio em cães da raça Poodle por meio da densitometria óptica radiográfica. Brazilan Journal of Veterinary Research and Animal Science, $v$. 42, n. 2, p. 89-99, 2005.

19 STERMAN, F. A. Avaliação da densidade mineral óssea em eqüinos atletas destinados ao enduro eqüestre. 47 f. 2002. Tese (Livre Docência) - Faculdade de Medicina Veterinária e Zootecnia, Universidade de São Paulo, São Paulo, 2002.

20 LOUZADA, M. J. Q. et al. Metodologia para a avaliação de densidade em imagem radiográfica. RBE Caderno de Engenharia Biomédica, v. 14, n. 2, p. 3747, 1998.

21 RAHAL, S. C.; MORTARI, A. C.; CAPORALI, E. H. G.; VULCANO, L. C.; SANTOS, F. A. M.; TAKAHIRA, R. K.; CROCCl, A. J. Densitometria óptica radiográfica na avaliação do hiperparateoidismo secundário nutricional induzido em gatos jovens. Ciência Rural, v. 32, n. 3, p. 421-425, 2002.

22 VULCANO, L. C.; CIARLINI, L. R. P.; MUNIZ, L. M. R.; CALDAS, E. L. C. Valores normais da densidade óssea do carpo ulnar em potros em crescimento da raça Quarto de Milha através da densitometria óptica radiográfica. A Hora Veterinária, v. 17, n. 100, p. 5254, 1997.

23 JUNQUEIRA, L. C.; CARNEIRO, J. Tecido ósseo. In: JUNQUEIRA, L. C.; CARNEIRO, J. Histologia básica. Rio de Janeiro: Guanabara-Koogan, 1990. p. 101-119.

24 BARDEN, H. S.; MAZESS, R. B. Bone densitometry in infants. Journal of Pediatrics, v. 113, n. 1, p. 172$177,1988$. 